\title{
Avaliação da cinética do epitélio corneano com marcadores de proliferação celular
}

\author{
Evaluation of the corneal epithelium kinetics using cell proliferation markers
}

\author{
Fernando Betty Cresta ${ }^{1}$ \\ Milton Ruiz Alves ${ }^{2}$
}

\begin{tabular}{|c|}
\hline RESUMO \\
\hline $\begin{array}{l}\text { Objetivo: Avaliar a cinética celular do epitélio corneano de coelhas em } \\
\text { três situações: controle, hiperproliferação e hipoproliferação celular, com } \\
\text { a utilização dos marcadores de proliferação celular BrdU, Ki-67/MIB-1 } \\
\text { e AgNOR. Métodos: Foram utilizadas quinze coelhas albinas que tiveram } \\
\text { seus olhos aleatoriamente divididos em } 3 \text { grupos (A, B e C). O grupo A } \\
\text { incluiu olhos que foram submetidos à instilação de tampão fosfato (total } \\
\text { de } 10 \text { olhos); o grupo B, instilação de tampão fosfato após a remoção de } \\
\text { uma área central do epitélio corneano de } 10 \text { mm (total de } 10 \text { olhos) e o } \\
\text { grupo C, instilação de } 5 \text {-fluoruracil em superfície ocular íntegra (total de } \\
10 \text { olhos). Resultados: Os resultados da média e desvio-padrão do número } \\
\text { de células marcadas pela BrdU nos grupos A, B e C foram, respectiva- } \\
\text { mente, de } 7,17 \pm 0,74 ; 35,00 \pm 3,01 \text { e } 0,22 \pm 0,1 \text { células marcadas por } 100 \\
\text { células basais. As diferenças entre os grupos foram estatisticamente sig- } \\
\text { nificantes. A média e o desvio padrão do número de células marcadas } \\
\text { utilizando o Ki-67 foram de } 7,55 \pm 1,22 \text { no grupo A; } 35,55 \pm 3,84 \text { no grupo } \\
\text { B e } 0,34 \pm 0,14 \text { no grupo C. As diferenças entre os grupos foram esta- } \\
\text { tisticamente significantes. A média e o desvio-padrão da medida da área } \\
\text { das NORs no grupo A foram de } 1,92 \pm 0,24 \text {, no grupo B foram de } 3,61 \\
\pm 0,27 \text { e no grupo C foram de } 1,71 \pm 0,26 \text {. Conclusões: Os marcadores } \\
\text { BrdU, Ki-67 e AgNOR apresentaram uma correlação positiva e esta- } \\
\text { tisticamente significante nas situações de proliferação celular avaliadas } \\
\text { (controle, hiperproliferação e hipoproliferação); o emprego do AgNOR } \\
\text { não permitiu identificar diferenças na proliferação celular nas situações } \\
\text { controle e hipoproliferação e houve maior concordância de resultados } \\
\text { entre a BrdU e o Ki-67 nas três situações de proliferação celular. }\end{array}$ \\
\hline
\end{tabular}

Descritores: Epitélio da córnea; Ciclo celular; Proliferação celular

Doutor, Médico Assistente do Hospital das Clínicas da Universidade de São Paulo - USP - São Paulo (SP) Brasil.

${ }^{2}$ Livre-Docente, Professor da Disciplina de Oftalmologia da Faculdade de Medicina da Universidade de São Paulo - USP - São Paulo (SP) - Brasil.

Endereço para correspondência: Rua Capote Valente, 432 - Cj. 155 - São Paulo (SP) - CEP 05409-001

E-mail: fbcresta@yahoo.com

Recebido para publicação em 11.07.2006

Última versão recebida em 11.09.2007

Aprovação em 12.09.2007

Nota Editorial: Depois de concluída a análise do artigo sob sigilo editorial e com a anuência do Dr. José Álvaro Pereira Gomes sobre a divulgação de seu nome como revisor, agradecemos sua participação neste processo.

\section{INTRODUÇ̃̃O}


de de processos fisiológicos e patológicos, tais como resposta ao uso de drogas, trauma ou cirurgia.

A cinética do epitélio corneano também pode ser alterada por várias drogas oftálmicas de uso tópico ${ }^{(4-8)}$. Estudos utilizando marcadores de proliferação celular demonstraram que drogas como 5-fluoruracil e mitomicina $\mathrm{C}$ diminuem, de forma importante, o número de mitoses no epitélio corneano ${ }^{(9-10)}$.

Grande número de trabalhos, utilizando marcadores de proliferação, foi realizado para estudo das neoplasias ${ }^{(11)}$. Independentemente das suas causas primárias, as neoplasias apresentam distúrbios no controle do ciclo celular que levam ao aumento da proliferação celular. O estudo da proliferação celular, ao lado de pesquisas sobre os eventos que regulam o ciclo celular, tem trazido informações importantes para o prognóstico e orientação terapêutica desses pacientes ${ }^{(12)}$.

Os marcadores de proliferação celular mais utilizados na prática clínica atualmente são: Bromodeoxiuridina (BrdU), Ki-67(MIB-1) e AgNOR. A bromodeoxiuridina (5-bromo-2'deoxiuridina), também designada por BrdU, é uma pirimidina análoga da timidina e é seletivamente incorporada ao DNA celular durante a fase $\mathrm{S}$ do ciclo celular ${ }^{(2-3)}$. Anticorpos antiBrdU, por meio da técnica imuno-histoquímica, permitem a identificação das células que incorporaram este precursor in vivo ou in vitro.

A incorporação da BrdU é uma alternativa ao método da timidina tritiada, sem o inconveniente da utilização de marcadores radioativos ${ }^{(13)}$. Além do estudo da cinética do ciclo celular, a bromodeoxiuridina também é útil na detecção de alterações cromossômicas; na avaliação da sensibilidade das células tumorais à quimioterapia ou radioterapia; na detecção da reatividade de linfócitos estimulados por antígenos e na avaliação dos efeitos inibitórios ou estimulatórios de substâncias na proliferação celular, tais como, fatores de crescimento ou citocinas ${ }^{(11)}$.

As AgNORs (regiões organizadoras nucleolares) são alças de DNA que possuem os genes do RNA ribossômico e estão localizadas nos cromossomos acrocêntricos 13, 14, 15, 21 e $22^{(14)}$. Proteínas ácidas não-histonas, tais como, RNA polimerase I, C23 ou nucleolina e B23 apresentam sítios de ligação com as AgNORs e estão envolvidas na organização funcional e estrutural dos nucléolos ${ }^{(15)}$. Essas proteínas apresentam afinidade pela prata, precipitando-se sob a forma de grumos no nucléolo, técnica que foi denominada $\mathrm{AgNOR}^{(16)}$.

O número médio de AgNORs por núcleo e/ou a medida da sua área refletem a atividade proliferativa de uma população celular $^{(11)}$. As AgNORs aumentam durante a fase G1, alcançando um valor máximo durante a fase $\mathrm{S}^{(15)}$.

Alguns autores consideram as AgNORs um indicador da atividade metabólica celular por sua relação com o RNA ribossômico e, desta forma, com a síntese de proteínas ${ }^{(1,11)}$.

Os métodos imuno-histoquímicos da proliferação celular baseiam-se na detecção de antígenos, como o Ki-67, cuja expressão tenha relação qualitativa ou quantitativa com uma ou mais fases do ciclo celular ${ }^{(17-18)}$.
Em 1983, foi descrita a preparação de um anticorpo monoclonal dirigido a um antígeno nuclear presente em células em proliferação, que foi chamado de Ki-6 $7^{(19)}$. A natureza molecular do antígeno identificado pelo Ki-67 permanece desconhecida, mas supõe-se que corresponda ao produto de uma seqüência gênica que codifica uma proteína não-histona de massa molecular aparente de 345-395 Kd, cuja presença é absolutamente necessária para a manutenção da proliferação celular ${ }^{(20)}$.

Esse antígeno é expresso durante todo o ciclo celular, exceto em G1 precoce e $\mathrm{G} 0$, sendo que sua expressão antigênica aumenta durante a última metade da fase $\mathrm{S}$, alcançando um pico máximo na fase $\mathrm{G} 2$ e mitose ${ }^{(21)}$.

A meia-vida do antígeno Ki-67 é curta, situando-se em torno de menos de uma hora após a mitose, o que é uma vantagem, já que garante apenas a marcação das células que tenham saído do ciclo celular(22).

A produção de dois novos anticorpos (MIB-1 e MIB-3), que são capazes de detectar a expressão da proteína Ki-67 em material embebido em parafina, tornou possível a avaliação da proliferação celular em material de arquivo, mesmo em blocos de parafina estocados por muitos anos ${ }^{(23)}$.

O objetivo deste trabalho é avaliar a cinética celular do epitélio corneano de coelhas em três situações de proliferação celular (controle, hipoproliferação e hiperproliferação), com a utilização dos marcadores de proliferação celular: Bromodeoxiuridina (BrdU), Ki-67(MIB-1) e AgNOR.

\section{MÉTODOS}

Utilizaram-se 15 coelhas albinas da raça Nova Zelândia, espécie Oryctolagus cuniculus, com idade entre dois e três meses, tratadas de acordo com as normas recomendadas pelo Colégio Brasileiro de Experimentação Animal.

As coelhas foram colocadas em gaiolas individuais e tiveram, para sua identificação, as orelhas direitas numeradas de 1 a 15 , com caneta hidrográfica. Após pesagem e exame na lâmpada de fenda para afastar inflamações ou alterações da superfície córneo-conjuntival e palpebral, tiveram seus olhos aleatoriamente divididos em 3 grupos para avaliar diferentes situações de proliferação celular: grupo A (controle), B (hiperproliferação celular) e C (hipoproliferação celular). Desta forma, o grupo $\mathrm{A}$ incluiu olhos que foram submetidos à instilação de tampão fosfato (total de 10 olhos); o grupo B, olhos que foram submetidos à instilação de tampão fosfato após a remoção de uma área central do epitélio corneano (total de 10 olhos) e o grupo $\mathrm{C}$, instilação de 5-fluoruracil na superfície ocular íntegra (total de 10 olhos).

Para serem submetidas à remoção da área central do epitélio corneano, as coelhas foram anestesiadas com injeções intramusculares de $0,6 \mathrm{ml} / \mathrm{kg}$ de peso de Rompum a $2 \%$ e de $1,05 \mathrm{ml} / \mathrm{kg}$ de peso de Ketalar. Após a irrigação da superfície córneo-conjuntival com solução de cloreto de sódio a $0,9 \%$, demarcou-se com trépano, não cortante, de 10 
mm de diâmetro (marca Petrovich), a área central do epitélio da córnea a ser removida nos olhos do grupo B. Desta forma, o epitélio corneano foi removido com um bisturi lâmina 15 , respeitando os limites demarcados pelo trépano. A comprovação da remoção foi verificada por meio da instilação de duas gotas de fluoresceína sódica a $2 \%$.

Nos olhos do grupo C, iniciou-se a instilação de colírio de 5fluoruracil $(10 \mathrm{mg} / \mathrm{ml}, \mathrm{pH}$ de 8,5 e osmolaridade de $307 \mathrm{mOsm} / \mathrm{l})$ e nos olhos dos grupos A e B, de tampão fosfato ( $\mathrm{pH}$ de 8,5 e osmolaridade de $307 \mathrm{mOsm} / \mathrm{l}$ ) na dosagem de uma gota a cada duas horas, seis vezes durante o dia por quatro dias (96 horas).

Em todos os animais, 15 horas antes do sacrifício, realizou-se uma injeção na veia marginal da orelha de solução contendo $50 \mathrm{mg} / \mathrm{kg}$ de peso de 5-bromo-2'-deoxiuridina (BrdU), diluída em $30,3 \mathrm{mg} / \mathrm{ml}$ de solução salina tamponada com fosfatos (PBS) com pH igual a 7,4.

Nos exames de controle, realizados a 96 horas do início do experimento, constatou-se reepitelização completa das córneas do grupo B. Após esses exames, todos os animais foram sacrificados e instilaram-se em ambos os olhos gotas de formol a $10 \%$ tamponado.

As córneas foram retiradas, fixadas em formol e incluídas na parafina. A identificação das córneas seguiu a seguinte padronização: o número do animal (1 a 15) acompanhado da especificação com relação ao olho direito ou esquerdo (D ou E, respectivamente).

Cortes histológicos de $5 \mu \mathrm{m}$ dos tecidos incluídos em parafina foram submetidos às técnicas imuno-histoquímicas para os marcadores BrdU e Ki-67 e histoquímica para a reação do AgNOR. Posteriormente, foram analisadas, sem que houvesse conhecimento prévio da droga administrada ou de que grupo provinha o animal.

Nas lâminas coradas pelos marcadores BrdU e Ki-67 foram contadas, sob microscopia óptica e em aumento de 400 vezes, o número total de células marcadas por 100 células basais. O número total de células contadas, por lâmina, foi de 1.000 células basais, de limbo a limbo, em todos os grupos.

Nas lâminas coradas pela técnica do AgNOR foram medidas as áreas das regiões organizadoras nucleolares (AgNORs) de 100 células basais do epitélio corneano. Essa medida foi realizada no Analisador de Imagens Digitais (marca Leica Q500IW Imaging Workstation, Image Processing and Analysis System; Software QWin -USA) acoplado a uma câmera de vídeo (marca JVC TK-C1380E) do Laboratório de Citologia do Hospital das Clínicas da Faculdade de Medicina da Universidade de São Paulo. Este sistema detectou, na imagem digitalizada, pixels que apresentavam limiar de coloração equivalente ao das AgNORs em estudo.

Os dados numéricos estatísticos foram apresentados por meio de médias aritméticas, desvios-padrão, medianas, quartis, intervalos de confiança e valores mínimos e máximos.

Como os dados neste estudo não possuíam distribuição gaussiana, foram utilizados testes estatísticos não-paramétricos: a) Prova de Kruskal-Wallis (H) - para comparações dos resultados obtidos com cada marcador nos diferentes grupos de proliferação celular.

b) Prova das comparações múltiplas pareadas de Dunn (Q) - para comparações múltiplas de cada marcador nos diferentes grupos de proliferação celular.

c) Correlação não-paramétrica de Spearman, para comparações dos resultados obtidos entre dois marcadores nos diferentes grupos de proliferação celular.

\section{RESULTADOS}

Células consideradas positivas, ou marcadas pela BrdU, apresentavam núcleos de coloração escura e estavam presentes na camada basal e suprabasal do epitélio, nos espécimes dos 3 grupos. A figura 1 ilustra o padrão de marcação da BrdU nos diferentes grupos. Em algumas lâminas (Figuras 1A e 1B), detectaram-se células aos pares (células recém-divididas).

Os valores do número total de córneas $(\mathrm{N})$, mediana, quartil inferior e superior, média, desvio-padrão, intervalo de confiança (IC), valores mínimo e máximo, assim como o resultado da prova de Kruskal-Wallis $(\mathrm{H})$ para o marcador BrdU nos diferentes grupos encontram-se na tabela 1.

A análise de variância, utilizando o teste de Kruskal-Wallis, demonstrou que as diferenças nos três grupos foram estatisticamente significativas $(\mathrm{H}=25,88 \mathrm{e} \mathrm{p}<0,0001 *)$. Os resultados da prova das comparações múltiplas pareadas de Dunn $\left(\mathrm{Q}<0,05^{*}\right)$ também foram estatisticamente significantes.

A figura 2 é uma representação gráfica das variações en-

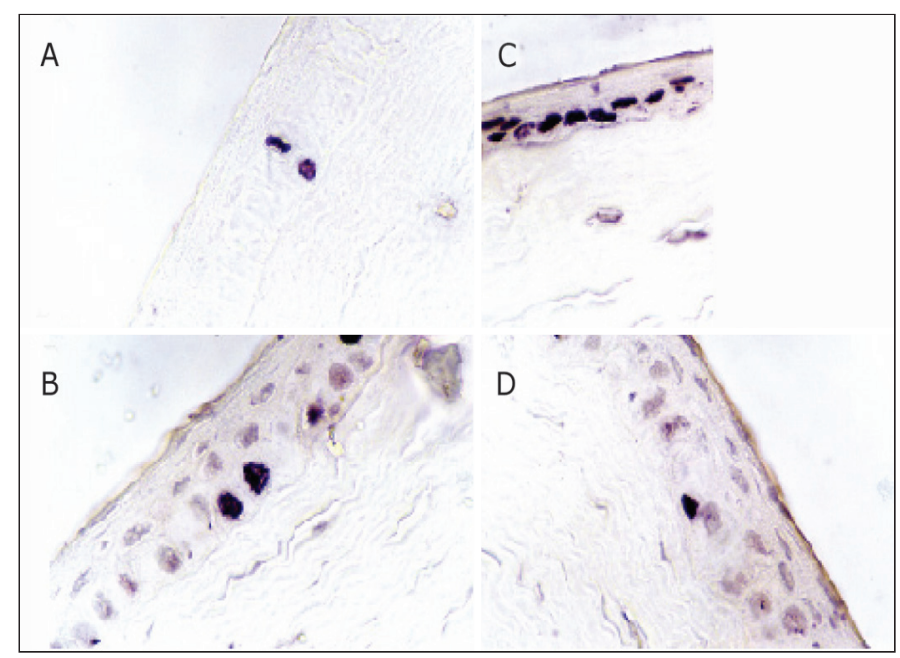

Figura 1 - (A e B) Microscopia óptica de espécime contendo epitélio corneano do grupo A. Nota-se a disposição das células marcadas na camada basal e suprabasal do epitélio (bromodeoxiuridina; contracoloração com Hematoxilina de Mayer, 400X). (C) Microscopia óptica de espécime contendo epitélio corneano do grupo B. Nota-se epitélio com poucas camadas (reparação do defeito epitelial). Presença de numerosas células marcadas nas camadas basal e suprabasal do epitélio (bromodeoxiuridina, 400X). (D) Microscopia óptica de espécime contendo epitélio corneano do grupo C (bromodeoxiuridina, 400X). 


\begin{tabular}{|c|c|c|c|c|c|c|c|c|c|c|}
\hline Grupos & $\mathbf{N}$ & MED & Q.I. & Q.S. & Média & DP & IC $-95,0 \%$ & IC $+95,0 \%$ & Valor min. & Valor máx. \\
\hline A & 10 & 7,05 & 6,60 & 7,70 & 7,17 & 0,74 & 6,64 & 7,70 & 6,20 & 8,50 \\
\hline \multirow[t]{2}{*}{ C } & 10 & 0,20 & 0,10 & 0,30 & 0,22 & 0,10 & 0,15 & 0,29 & 0,10 & 0,40 \\
\hline & & $H=25,88$ & & $<0,00$ & & & & & & \\
\hline
\end{tabular}

contradas no número de células marcadas usando o marcador BrdU nos 3 grupos (A, B e C).

A figura 3 ilustra o padrão de marcação do Ki-67 nos diferentes grupos. As células marcadas pelo Ki-67 apresentavam núcleos de coloração marrom e estavam presentes na camada basal e suprabasal do epitélio. Células aos pares (células recém-divididas) podiam ser detectadas em algumas lâminas (Figuras 3A e 3B).

Os valores do número total de córneas $(\mathrm{N})$, mediana, quartil inferior e superior, média, desvio-padrão, intervalo de confiança (IC), valores mínimo e máximo, assim como o resultado da prova de Kruskal-Wallis $(\mathrm{H})$ para o marcador Ki67 nos diferentes grupos encontram-se na tabela 2.

As diferenças nos resultados obtidos nos 3 grupos foram estatisticamente significantes pela prova de Kruskal-Wallis $\left(\mathrm{H}=25,85\right.$ e $\left.\mathrm{P}<0,0001^{*}\right)$. Os resultados da prova das comparações múltiplas pareadas de Dunn $\left(\mathrm{Q}<0,05^{*}\right)$ também foram estatisticamente significantes.

A figura 4 é uma representação gráfica das variações encontradas no número de células marcadas usando o marcador Ki-67 nos 3 grupos (A, B e C).

As regiões organizadoras nucleolares (AgNORs), coradas pela prata, foram detectadas como grânulos escurecidos, por vezes de coloração marrom, localizados no interior dos núcleos celulares. As AgNORs foram detectadas nas células de todas as camadas do epitélio corneano, mas só foram analisadas as AgNORs das células da camada basal. A figura 5 ilustra o padrão de marcação do AgNOR nos diferentes grupos.

Os valores do número total de córneas $(\mathrm{N})$, mediana, quartil inferior e superior, média, desvio-padrão, intervalo de confiança (IC), valores mínimo e máximo, assim como o resultado da prova de Kruskal-Wallis (H) para a medida da área das NORs, nos diferentes grupos, encontram-se na tabela 3. Não foi possível realizar a leitura da lâmina 8 do grupo $C$ (má qualidade técnica do espécime).

As diferenças nos resultados obtidos foram estatisticamente significantes utilizando o teste de Kruskal-Wallis $(\mathrm{H}=20,36$ e $\mathrm{p}<0,0001 *)$. Porém, a prova de Dunn demonstrou que a comparação entre os grupos $\mathrm{A}$ e $\mathrm{C}$ não foi estatisticamente significante $(\mathrm{Q}>0,05)$.

A figura 6 é uma representação gráfica das variações encontradas nas medidas das áreas das NORs nos 3 grupos (A, B e C).

A comparação dos resultados obtidos com os marcadores BrdU, Ki-67 e AgNOR foi realizada com o teste de correlação não-paramétrico de Spearmam. O teste de Spearman demons- trou uma correlação positiva e significante entre os marcadores BrdU e Ki-67 ( $r=0,94582$; $\mathrm{p}=0,0001^{*}$, Figura 7A), Ki-

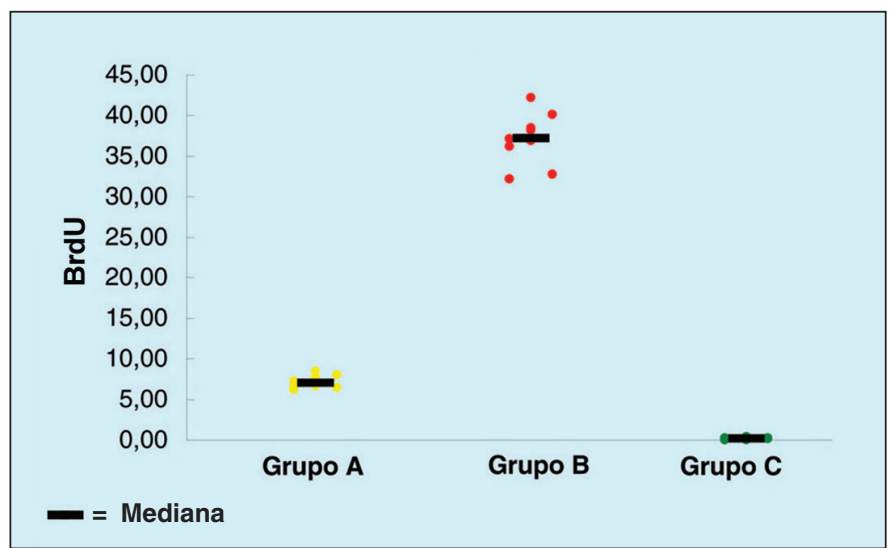

Figura 2 - Representação gráfica do número de células marcadas pela BrdU nos diferentes grupos $\left(p<0,0001^{\star}\right)$

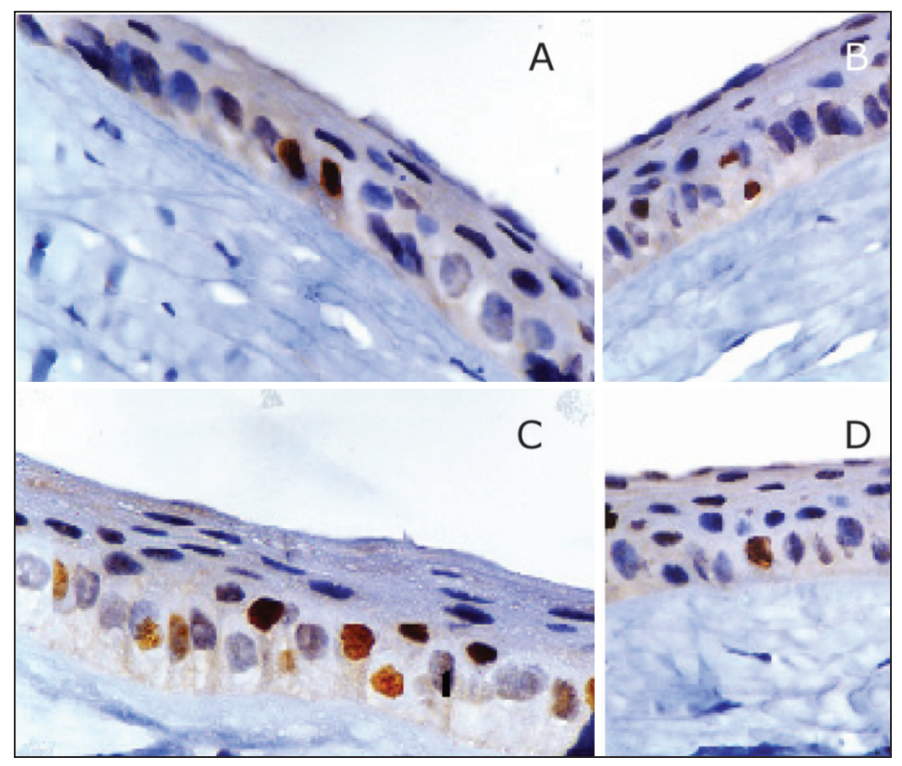

Figura 3 - (A e B) Microscopia óptica de espécime contendo epitélio corneano do grupo A. Nota-se a disposição das células marcadas, com coloração marrom, na camada basal do epitélio (MIB-1/Ki-67, 400X). (C) Microscopia óptica de espécime contendo epitélio corneano do grupo B. Presenca de numerosas células marcadas nas camadas basal e suprabasal do epitélio. Em algumas células, nota-se presença de marcação dos nucléolos (seta) (MIB-1/Ki-67, 400X). (D) Microscopia óptica de espécime contendo epitélio corneano do grupo C (MIB-1/Ki$67,400 X)$. 


\begin{tabular}{|c|c|c|c|c|c|c|c|c|c|c|}
\hline Grupos & $\mathbf{N}$ & MED & Q.I. & Q.S. & Média & DP & IC $-95,0 \%$ & IC $+95,0 \%$ & Valor min. & Valor máx. \\
\hline A & 10 & 7,55 & 6,90 & 8,50 & 7,55 & 1,22 & 6,67 & 8,43 & 5,50 & 9,60 \\
\hline \multirow[t]{2}{*}{ C } & 10 & 0,35 & 0,20 & 0,50 & 0,34 & 0,14 & 0,24 & 0,44 & 0,10 & 0,50 \\
\hline & & & $H=25,85$ & & $p<0,000$ & & & & & \\
\hline
\end{tabular}

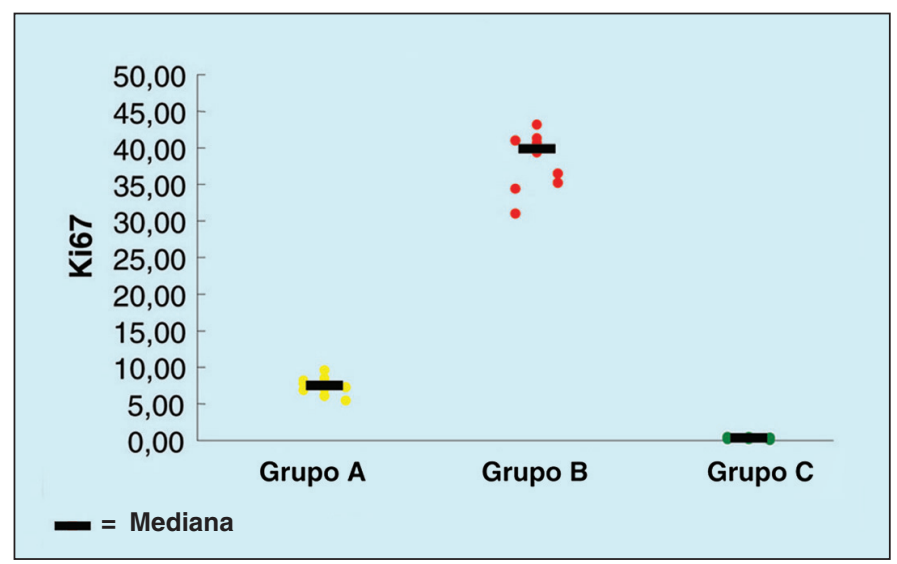

Figura 4 - Representação gráfica do número de células marcadas pelo Ki-67 nos diferentes grupos $\left(p<0,0001^{*}\right)$

67 e $\operatorname{AgNOR}\left(\mathrm{r}=0,85267 ; \mathrm{p}=0,0001^{*}\right.$, Figura $\left.7 \mathrm{~B}\right)$ e $\mathrm{BrdU}$ e AgNOR (r=0,86546; $\mathrm{p}=0,0001 *$, Figura $7 \mathrm{C})$.

\section{DISCUSSÃO}

O estudo da cinética do epitélio corneano é importante para a compreensão de uma grande variedade de processos fisiológicos e patológicos. Os métodos imuno-histoquímicos e histoquímicos, cada vez mais difundidos entre os laboratórios de patologia e com melhores resultados à medida que as técnicas vão se aprimorando, já se encontram entre os mais úteis e comumente usados para avaliação da proliferação celular ${ }^{(24)}$.
Nesta investigação, as médias e os desvios-padrão das células marcadas pela $\mathrm{BrdU}$ nos grupos $\mathrm{A}, \mathrm{B}$ e $\mathrm{C}$ foram, respectivamente, de 7,17 $\pm 0,74 ; 37,15 \pm 3,01$ e $0,22 \pm 0,10$ células por 100 células basais (Tabela 1). As diferenças entre os grupos foram estatisticamente significantes pela prova de Dunn $\left(\mathrm{p}<0,05^{*}\right)$. Proporcionalmente, o grupo que foi submetido à desepitelização de córnea (grupo B) apresentou um aumento no número de células marcadas de 5,18 vezes em relação ao grupo com epitélio normal (grupo A); por outro lado, a instilação do 5-fluoruracil por 4 dias diminuiu o número de células marcadas 32,5 vezes em relação ao grupo controle.

O padrão de marcação obtido com a BrdU (Figuras 1), em que as células marcadas estavam presentes na camada basal e suprabasal do epitélio (algumas dispostas em pares), foi semelhante ao referido na literatura ${ }^{(13,25-26)}$.

Raska et al., em 1991, relataram que o tempo de exposição à BrdU influencia as taxas de marcação e o intervalo de tempo ideal dependeria da duração do ciclo celular ${ }^{(27)}$. Nesta pesquisa, optou-se pela injeção endovenosa do reagente 15 horas antes da retirada das córneas, para diminuir as variações das taxas mitóticas das células epiteliais decorrentes do ritmo circadiano com pico de mitose às 9 horas ${ }^{(28)}$.

A BrdU não é utilizada como rotina na prática clínica, pelo fato de ser incorporada ao DNA celular, o que poderia predispor a mutações celulares. Apesar do surgimento de novos marcadores de proliferação histoquímicos e imunohistoquímicos, como o AgNOR e o Ki-67, poucos trabalhos avaliaram suas aplicações no epitélio corneano e sua correlação com o marcador padrão BrdU.

A média e o desvio-padrão do número de células marcadas

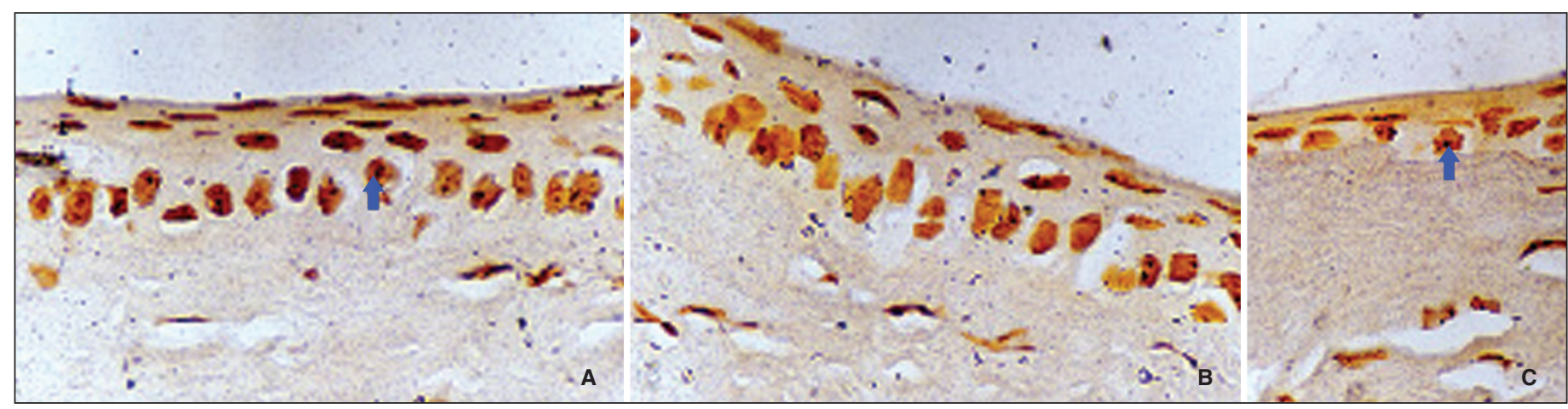

Figura 5 - (A) Microscopia óptica de espécime contendo epitélio corneano do grupo A. Nota-se a presença das NORs (seta) em todas as camadas epiteliais (AgNOR, 400X). (B) Microscopia óptica de espécime contendo epitélio corneano do grupo C (AgNOR, 400X). (C) Microscopia óptica de espécime contendo epitélio corneano do grupo B. Presença de numerosas NORs (seta) e epitélio com poucas camadas (AgNOR, 400X). 


\begin{tabular}{|c|c|c|c|c|c|c|c|c|c|c|}
\hline Grupos & $\mathbf{N}$ & MED & Q.I. & Q.S. & Média & DP & IC $-95,0 \%$ & IC $+95,0 \%$ & Valor min. & Valor máx. \\
\hline A & 10 & 1,94 & 1,82 & 2,10 & 1,92 & 0,24 & 1,74 & 2,09 & 1,41 & 2,25 \\
\hline \multirow[t]{2}{*}{ C } & 9 & 1,74 & 1,59 & 1,87 & 1,71 & 0,26 & 1,53 & 1,90 & 1,29 & 2,11 \\
\hline & & & $=20,3$ & & $0<0,000$ & & & & & \\
\hline
\end{tabular}

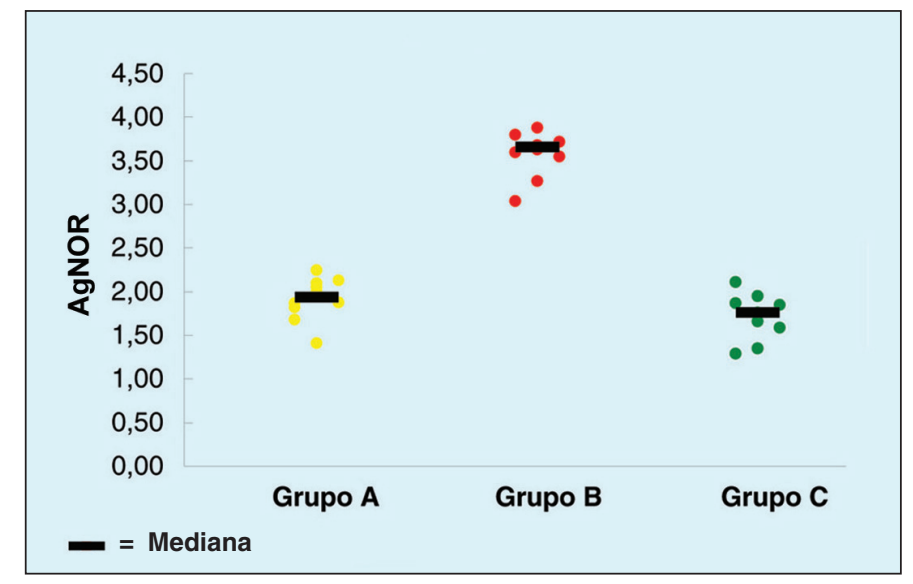

Figura 6 - Representação gráfica das medidas das áreas das NORs nos diferentes grupos $\left(p<0,0001^{\star}\right)$

(por 100 células basais) utilizando o Ki-67 foi de 7,55 $\pm 1,22$ no grupo A; $38,30 \pm 3,84$ no grupo $\mathrm{B}$ e $0,34 \pm 0,14$ no grupo $\mathrm{C}$ (Tabela 2). As diferenças entre os grupos foram estatisticamente significantes pela prova de Dunn $\left(\mathrm{p}<0,05^{*}\right)$.

No presente trabalho, o padrão de marcação com o Ki-67 variou: algumas células apresentavam leve coloração marrom, localizada principalmente no nucléolo, enquanto outras, intensa marcação em toda a região nuclear (Figura 3). Esse tipo de variação na marcação é descrito na literatura, em que o padrão típico nucleolar na interfase pode se modificar para padrões granulares ou pontilhados na mitose, quando o nucléolo se desintegra ${ }^{(29)}$. Por ser um método altamente específico, vários autores consideram que mesmo células minimamente marcadas devam ser consideradas positivas, ou seja, dentro do ciclo celular ${ }^{(30)}$.

O anticorpo monoclonal MIB-1, utilizado neste trabalho, reconhece o antígeno Ki-67, mas, ao contrário do anticorpo Ki-67 original, pode marcar células em proliferação em materiais fixados na formalina e emblocados na parafina ${ }^{(12)}$.

As taxas de marcação do Ki-67, em diferentes tecidos, são comparáveis às obtidas com outros métodos de avaliação da proliferação celular, tais como, contagem de mitoses, citometria de fluxo, incorporação da timidina tritiada e $\mathrm{BrdU}^{(31-33)}$.

Não foram encontrados relatos na literatura sobre a utilização da técnica do AgNOR no epitélio corneano.

A média e o desvio-padrão da medida da área das AgNORs no grupo A foram de 1,92 $\pm 0,24$; no grupo B, 3,61 $\pm 0,27$ e no grupo $\mathrm{C}, 1,71 \pm 0,26$ (Tabela 3). A análise dos resultados ob- tidos, utilizando a técnica do AgNOR, demonstrou que as diferenças existentes entre os grupos $\mathrm{B}$ e $\mathrm{C}$, assim como $\mathrm{B}$ e A, foram estatisticamente significantes. Por outro lado, a comparação dos resultados entre o grupo $\mathrm{A}$ e $\mathrm{C}$ não demonstrou diferenças estatisticamente significantes pela prova de Dunn $(\mathrm{p}>0,05)$. O tamanho da amostra pode ter influenciado esse resultado. Trabalhos futuros com a utilização de amostras maiores (a estimativa estatística do tamanho da amostra para o marcador AgNOR seria de 20 olhos) podem confirmar ou refutar esses resultados.

As AgNORs, além de sua função na proliferação celular, também participam da transcrição celular (produção de proteínas) ${ }^{(34)}$. Desta forma, mesmo células com baixa atividade mitótica (mas com produção de proteínas) podem apresentar um número mínimo de NORs por núcleo ${ }^{(35)}$, o que explicaria a ausência de diferenças entre os grupos $\mathrm{A}$ e $\mathrm{C}$.

A utilização do analisador de imagem digital com resolução em pixels para a medida da área das NORs, método utilizado neste trabalho, diminui a variação subjetiva entre observadores decorrente da leitura manual ${ }^{(36-37)}$.

Os marcadores BrdU, Ki-67 e AgNOR apresentaram uma correlação positiva e estatisticamente significante nos diferentes grupos (Figura 7).

A técnica do AgNOR, utilizada nesta investigação pela primeira vez para avaliar a atividade proliferativa do epitélio corneano, apresentou correlação positiva com os outros métodos de avaliação da proliferação celular. Essa técnica é pouco trabalhosa, apresenta baixo custo e pode ser utilizada em material processado rotineiramente ${ }^{(15)}$.

Neste estudo, o Ki-67 foi capaz de detectar diferenças no número de células marcadas em três situações de proliferação celular (controle, hiperproliferação e hipoproliferação) e também apresentou correlação positiva com os outros marcadores de proliferação celular avaliados. Dentre as suas vantagens, podemos citar: relação bem definida com o ciclo celular, facilidade de realização e pequena susceptibilidade a fatores técnicos, tais como, tempo de fixação e diluição de anticorpos $^{(29,38-39)}$.

Durante a cicatrização corneana, o epitélio necessita migrar para cobrir o defeito epitelial, proliferar (mitose) e restabelecer suas adesões. $\mathrm{O}$ uso de marcadores da proliferação celular, objeto de estudo deste trabalho, pode ser utilizado tanto in vivo quanto in vitro (cultura de células) para avaliação do efeito de diferentes tratamentos ${ }^{(27,40)}$.

No futuro, a associação de métodos que avaliem diferen- 


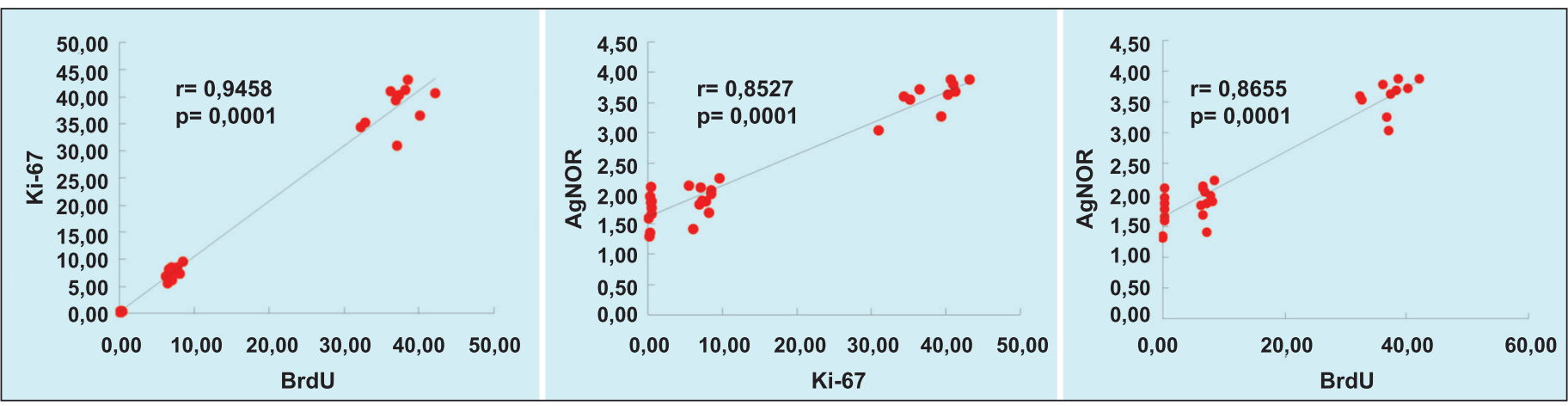

Figura 7- (A) Representação gráfica da correlação entre os marcadores Ki-67 e BrdU. (B) Representação gráfica da correlação entre os marcadores AgNOR e Ki-67. (C) Representação gráfica da correlação entre os marcadores AgNOR e BrdU.

tes aspectos da cinética do epitélio corneano proporcionará uma idéia mais precisa da verdadeira atividade proliferativa dessa população celular. Tais informações fornecerão subsídios que certamente favorecerão um melhor entendimento da fisiologia epitelial, assim como sua resposta frente ao uso de drogas ou cirurgias.

\section{CONCLUSÕES}

Nas condições deste estudo, conclui-se que:

1 - Os marcadores BrdU e Ki-67 foram capazes de detectar diferenças na cinética celular nas três situações de proliferação celular avaliadas (controle, hiperproliferação e hipoproliferação).

2 - O emprego do AgNOR não permitiu identificar diferenças na proliferação celular entre as situações controle e hipoproliferação.

3 - Os marcadores BrdU, Ki-67 e AgNOR apresentaram correlação positiva nas três situações de proliferação celular.

\section{ABSTRACT}

Purpose: In order to maintain its clear and uniform structure, the corneal epithelium needs constant equilibrium between production (division) and desquamation of its epithelial cells. The author aimed to evaluate the cell kinetics of corneal epithelium of rabbits in three situations (control, hypoproliferation and hyperproliferation) using BrdU, Ki-67/MIB1 and AgNORs proliferation markers. Methods: Fifteen white female rabbits had their eyes randomly divided into three groups (A, B and. C). Group A included eyes submitted to phosphate buffer saline instillation (total 10 eyes); group B, instillation of phosphate buffer saline after removing a $10 \mathrm{~mm}$ central area of the corneal epithelium (total 10 eyes) and group $\mathrm{C}$, instillation of 5-fluorouracil in normal epithelium (total 10 eyes). Results: The results of the mean number and standard deviation of the marked cells using $\mathrm{BrdU}$ in groups $\mathrm{A}, \mathrm{B}$ e C were, respectively, $7.17 \pm 0.74 ; 35.00 \pm 3.01$ e $0.22 \pm 0.1$ marked cells per 100 basal cells. Differences among groups were statistically significant. The mean number and standard deviation of the labelled cells using Ki-67 were $7.55 \pm 1.22$ in group A; $35.55 \pm 3.84$ in group B and $0.34 \pm 0.14$ in group C. Differences among groups were statistically significant. The mean area and standard deviation of NORs in group A were $1.92 \pm 0.24$, in group B, $3.61 \pm 0.27$ and in group C, $1.71 \pm$ 0.26. Conclusions: The markers BrdU, Ki-67 and AgNOR showed a positive correlation with statistical significance among the cellular proliferation situations studied (control, hypoproliferation and hyperproliferation); the AgNOR did not show statistically significant differences among the control and hypoproliferation situations and there was more agreement in the results among markers BrdU and Ki-67 in three cell proliferation situations.

Keywords: Epithelium, corneal; Cell cycle; Cell proliferation

\section{REFERÊNCIAS}

1. Wilson SE, Mohan RR, Hong JW, Lee JS, Choi R, Mohan RR. The wound healing response after laser in situ keratomileusis and photorefractive keratectomy: elusive control of biological variability and effect on custom laser vision correction. Arch Ophthalmol. 2001;119(6):889-96.

2. Fagerholm P, Hamberg-Nyström H, Tengroth B. Wound healing and myopic regression following photorefractive keratectomy. Acta Ophthalmol (Copenh). 1994;72(2):229-34

3. Gauthier CA, Epstein D, Holden BA, Tengroth B, Fagerholm P, HambergNyström H, Sievert R. Epithelial alterations following photorefractive keratectomy for myopia. J Refract Surg. 1995;11(2):113-8.

4. Mattar DB, Alves MR, Silva MHT, José NK. Estudo da influência da aplicação subconjuntival da mitomicina $\mathrm{C}$ na reparação de defeito epitelial corneano, em coelhas. Arq Bras Oftalmol. 1995;58(1):65-7.

5. Alves MR, José NK. Influência do uso tópico de mitomicina $C$ na reparação de defeito epitelial corneano central em coelhas. Arq Bras Oftalmol. 1996; 59(1):77-82.

6. Alves MR, Saldiva PHN, Lemos M, José NK. Efeitos do uso tópico da mitomicina $\mathrm{C}$ no epitélio corneano de coelhas: análise histopatológica pela morfometria. Arq Bras Oftalmol. 1996;59(5):431-7.

7. Mattar DB, Alves MR, Silva MHT, Kara-José N. Regeneração do epitélio corneano central após o uso tópico de mitomicina C. Arq Bras Oftalmol. 1996; 59(3):255-8, 260.

8. Medeiros FW, Alves MR, Silva MHT, Cresta FB, José NK. Influência do uso tópico de proparacaína na reparação de defeito epitelial corneano. Arq Bras Oftalmol. 2000;63(2):119-22.

9. Crooke ST, Bradner WT. Mitomycin C: a review. Cancer Treat Rev. 1976; 3(3):121-39. Review. 
10. Shapiro MS, Thoft RA, Friend J, Parrish RK, Gressel MG. 5-Fluorouracil toxicity to the ocular surface epithelium. Invest Ophthalmol Vis Sci. 1985; 26(4):580-3.

11. van Diest PJ, Brugal G, Baak JP. Proliferation markers in tumours: interpretation and clinical value. J Clin Pathol. 1998; 51(10):716-24. Comment in: J Clin Pathol. 1999;52(7):550.

12. Rabenhorst SH, Burini RC, Schmitt FCL. Marcadores de proliferação celular. Rev Bras Patol Clín=Braz J Med Biol Res. 1993;29(1):24-9.

13. Szerenyi K, Wang X, Gabrielian K, LaBree L, McDonnell PJ. Immunochemistry with 5-bromo-2-deoxyuridine for visualization of mitotic cells in the corneal epithelium. Cornea. 1994;13(6):487-92.

14. Hall PA, Crocker J, Watts A, Stansfeld AG. A comparison of nucleolar organizer region staining and Ki-67 immunostaining in non-Hodgkin's lymphoma. Histopathology. 1988;12(4):373-81.

15. Derenzini M, Pession A, Trerè D. Quantity of nucleolar silver-stained proteins is related to proliferating activity in cancer cells. Lab Invest. 1990; 63(1):137-40. Comment in: Lab Invest. 1991;64(5):718-9.

16. Goodpasture C, Bloom SE. Visualization of nucleolar organizer regions in mammalian chromosomes using silver staining. Chromosoma. 1975;53(1): 37-50

17.Hall PA, Levison DA. Review: assessment of cell proliferation in histological material. J Clin Pathol. 1990;43(3):184-92.

18. Holfstädter F, Knüchel R, Rüschoff J. Cell proliferation assessment in oncology. Virchows Arch. 1995;427(3):323-41.

19. Gerdes J, Schwab U, Lemke H, Stein H. Production of a mouse monoclonal antibody reactive with a human nuclear antigen associated with cell proliferation. Int J Cancer. 1983;31(1):13-20.

20. Gerdes J, Li L, Schlueter C, Duchrow M, Wohlenberg C, Gerlach C, et al Imunobiochemical and molecular biologic characterization of the cell proliferation-associated nuclear antigen that is defined by monoclonal antibody Ki-67. Am J Pathol. 1991;138(4):867-73.

21. Sasaki K, Murakami T, Kawsaki M, Takahashi M. The cell cycle associated change of the Ki-67 reactive nuclear antigen expression. J Cell Physiol. 1987;133(3):579-84

22. Bruno S, Darzynkiewicz Z. Cell cycle dependent expression and stability of the nuclear protein detected by Ki-67 antibody in HL-60 cells. Cell Prolif. 1992;25(1):31-40.

23. Cattoretti G, Becker MH, Key G, Duchrow M, Schlüter C, Galle J, Gerdes J. Monoclonal antibodies against recombinant parts of the Ki-67 antigen (MIB1 and MIB-3) detect proliferating cells in microwave-processed formalin-fixed paraffin sections. J Pathol. 1992;168(4):357-63.

24. Mello ES, Alves VAF. Marcadores de proliferação celular. In: Alves VAF, Bacchi CE, Vassalo J, organizadores. Manual de imuno-histoquímica. São Paulo: Sociedade Brasileira de Patologia; 1999. p.182-94.

25. Haddad A. Renewal of the rabbit corneal epithelium as investigated by autoradiography after intravitreal injection of 3H-thymidine. Cornea. 2000;19(3):378-83.
26. Zagon IS, Sassani JW, Ruth TB, McLaughlin PJ. Cellular dynamics of corneal wound re-epithelialization in the rat. III. Mitotic activity. Brain Res. 2000;882(1-2):169-79.

27. Raska I, Michel LS, Jarnik M, Dundr M, Fakan S, Gasser S, et al. Ultrastructural cryoimmunocytochemistry is a convenient tool for the study of DNA replication in cultured cells. J Electron Microsc Tech. 1991;18(2):91-105.

28. Haskjold E, Refsum SB, Bjerknes R. Circadian variation in the mitotic rate of the rat corneal epithelium. Cell divisions and migration are analyzed by a mathematical model. Virchows Arch B Cell Pathol Incl Mol Pathol. 1989;58(2):123-7.

29. Mello ES, Alves VAF. Determinação da fração de proliferação celular no carcinoma de mama através da marcação imuno-histoquímica do antígeno nuclear Ki-67: uma comparação dos métodos visuais para avaliação da prática diária. J Bras Patol. 1999;35(4):200-5.

30. Verheijen R, Kuijpers HJ, Schlingemann RO, Boehmer AL, van Driel R, Brakenhoff GJ, Ramaekers FC. Ki-67 detects a nuclear matrix-associated proliferation-related antigen. I. Intracellular localization during interphase. J Cell Sci. 1989;92(Pt 1):123-30.

31. Kawauchi K, Sato Y, Furuya T, Watanaber S. Determination of proliferative fractions detected by immunohistochemistry with the monoclonal antibodies to bromodeoxyuridine and $\mathrm{Ki}-67$ in malignant lymphomas. Hematol Oncol. $1989 ; 7(4): 257-65$

32. Hitchcock CL. Ki-67 staining as a means to simplify analysis of tumor cell proliferation. Am J Clin Pathol. 1991:96(4):444-6.

33. Yu CC, Filipe MI. Update on proliferation-associated antibodies applicable to formalin-fixed paraffin-embedded tissue and their clinical applications. Histochem J. 1993;25(12):843-53.

34. Underwood JC. AgNOR measurements as indices of proliferation, ploidy and prognosis. J Clin Pathol. 1995;48(5):M239-M240.

35. Kanitakis J, Hoyo E, Chouvet B, Trivolet J, Faure M, Claudy A. Keratinocyte proliferation in epidermal keratinocyte disorders evaluated through $\mathrm{PCNA} /$ cyclin immunolabelling and AgNOR counting. Acta Derm Venereol. 1993;73(5):370-5.

36. Rüschoff J, Plate KH, Contractor H, Kern S, Zimmermann R, Thomas C. Evaluation of nucleolus organizer regions (NORs) by automatic image analysis: a contribution to standardization. J Pathol. 1990;161(2):113-8.

37. Derenzini $M$, Trerè $D$. Importance of interphase nucleolar organizer regions in tumor pathology. Virchows Arch B Cell Pathol Incl Mol Pathol. 1991;61(1):1-8.

38. McCormick D, Yu C, Hobbs C, Hall PA. The relevance of antibody concentration to the immunohistological quantification of cell proliferation-associated antigens. Histopathology. 1993;22(6):543-7.

39. Schwarting R. Little missed markers and Ki-67. Lab Invest. 1993;68(6):597-9.

40. Poon AC, Geerling G, Dart JK, Fraenkel GE, Daniels JT. Autologous serum eyedrops for dry eyes and epithelial defects: clinical and in vitro toxicity studies. Br J Ophthalmol. 2001;85(10):1188-97. Comment in: Br J Ophthalmol. 2002;86(7):832. 